\title{
Decreased miR-143 and increased miR-21 placental expression levels are associated with macrosomia
}

\author{
JI-TAI ZHANG $^{1}$, QIAN-YING CAI ${ }^{1}$, SI-SI JI ${ }^{1}$, HENG-XIN ZHANG $^{1}$, \\ YU-HUAN WANG ${ }^{2}$, HONG-TAO YAN ${ }^{1}$ and XIN-JUN YANG ${ }^{1}$ \\ ${ }^{1}$ Department of Preventive Medicine, School of Environmental Science and Public Health, Wenzhou Medical University, \\ Wenzhou, Zhejiang 325035; ${ }^{2}$ Department of Obstetrics, Yuying Children's Hospital of Wenzhou Medical University, \\ Wenzhou, Zhejiang 325027, P.R. China
}

Received May 5, 2015; Accepted January 8, 2016

DOI: $10.3892 / \mathrm{mmr} .2016 .4892$

\begin{abstract}
Macrosomia, a birth weight $\geq 4,000 \mathrm{~g}$, is associated with maternal and infant health problems. The dysregulation of microRNAs (miRNAs) in the placenta is associated with adverse birth outcomes, yet whether aberrantly expressed placental miRNAs are associated with macrosomia remains unknown. The aim of the current study was to characterize the expression of three placental miRNAs (miR-6, -21 and -143) and evaluate their association with macrosomia. The miRNA expression in placental tissues from 67 macrosomic pregnancies and 64 normal pregnancies were analyzed using reverse transcription-quantitative polymerase chain reaction. The expression of miR-21 was observed to be elevated in macrosomic placenta compared with control samples, while miR-143 expression was significantly lower than in control placenta $(\mathrm{P}<0.05)$. No significant differences were identified in the miR-16 expression levels between the groups $(\mathrm{P}=0.955)$. Following division of miRNA expression levels by quartile, logistic regression models demonstrated that the odds of macrosomia increased with miR-21 expression quartile: $\mathrm{Q} 2$, odds ratio $(\mathrm{OR})=6.67$ [95\% confidence interval (CI), 1.39-32.05]; Q3, OR=4.10 (95\% CI, 0.88-19.11); Q4, $\mathrm{OR}=16.19$ (95\% CI, 2.46-106.68). Conversely, higher levels of miR-143 expression were protective against macrosomia: Q2, OR=0.22 (95\% CI, 0.049-0.98); Q3, OR=0.11 (95\% CI, 0.024-0.55), and Q4, OR=0.16 (95\% CI, 0.032-0.79). Thus, statistical analysis demonstrated that high levels of miR-21 expression and low levels of miR-143 expression predict the risk for macrosomia, indicating an interaction between the two
\end{abstract}

Correspondence to: Professor Xin-Jun Yang or Professor Hong-Tao Yan, Department of Preventive Medicine, School of Environmental Science and Public Health, Wenzhou Medical University, Center North Road, University Town, Wenzhou, Zhejiang 325035, P.R. China

E-mail: xjyang@wzmc.edu.cn

E-mail: htyan@wzmc.edu.cn

Key words: macrosomia, microRNA, placenta, normal pregnancy
miRNAs. Bioinformatic analysis suggested that they are likely to function in the mitogen-activated protein kinases signaling pathway to influence the risk of macrosomia. The results of the present study provide evidence that placental miR-21 and -143 are important in the formation of macrosomia.

\section{Introduction}

Fetal macrosomia has been inconsistently defined as a birth weight of $>4,000,4,500$ or $5,000 \mathrm{~g}$, regardless of gestational age $(1,2)$. In China, the most widely used definition of macrosomia is a birth weight $\geq 4,000 \mathrm{~g}$. Macrosomia can lead to adverse birth outcomes for the newborn, including perinatal asphyxia, neonatal mortality and shoulder dystocia $(1,3)$. In addition, mothers delivering macrosomic fetuses are at an increased risk of experiencing prolonged labor, C-section, abnormal hemorrhage and perineal laceration $(4,5)$. Numerous studies have indicated that high birth weight is associated with long-term health risks for the newborn, including an increased risk of obesity, diabetes and certain types of cancer (6-9). In the past two to three decades, the incidence of macrosomia in developed countries has increased by $15-25 \%$ (2). In China, the macrosomia occurrence rate increased from 6.5\% in 2006 (10) to $7.3 \%$ in 2011 (11). However, the mechanisms responsible for fetal macrosomia remains poorly understood.

A large body of research has indicated that epigenetic alterations in placental tissues are associated with adverse pregnancy outcomes and fetal programming (12-14). MicroRNAs (miRNAs) are short noncoding RNA molecules ( 22 nucleotides in length) and are important in post-transcriptional gene regulation through their binding with hundreds of different mRNAs (15). A wide range of biological activities are affected by miRNAs, including cellular proliferation, differentiation, apoptosis and the processes of numerous diseases, including cancer, obesity, insulin resistance and diabetes $(16,17)$. Previous investigations have demonstrated that aberrant expression of a number of miRNAs in the placenta was associated with low birth weight and preeclampsia $(18,19)$. Maccani et al $(20)$ reported that decreased levels of placental miR-16 and -21 were associated with poor fetal growth. In addition, miR-143 was implicated as a crucial regulator of adipogenesis (21). Since evidence suggested that miR-16, -21 and -143 are important in 
fetal development, the current study sought to further characterize the association of these miRNAs with macrosomia.

The present study examined the expression of miRs-16, -21 and -143 in the placenta of macrosomic and normal pregnancies and demonstrated miRNA dysregulation in macrosomic placenta.

\section{Materials and methods}

Study population. Subjects were recruited at Yuying Children's Hospital of Wenzhou Medical University (Wenzhou, China). Macrosomia was defined as a neonate with a birth weight $\geq 4,000 \mathrm{~g}$. Normal birth weight was defined as 2,500-3,999 g. Samples from macrosomia cases and controls were collected from women between the ages of 18 and 42 years with healthy pregnancies (i.e. pregnancies without hypertension, hepatitis, heart disease, psychological disorders, gestational diabetes or impaired glucose tolerance), whose infants were full-term ( $\geq 37$ weeks) and viable, with no known genetic disorders. Maternal weight gain during pregnancy was divided into three levels, including low, moderate and high, according to recommendations from the Institute of Medicine (22). A total of 67 macrosomic and 64 control pregnancies were selected. All subjects provided written informed consent to participate in the current study, and the research protocol was approved by the Ethics Committee of Wenzhou Medical University.

Placenta collection. A placental biopsy of $\sim 1 \mathrm{~g}$ was excised from the maternal side of each placenta, $2 \mathrm{~cm}$ from the umbilical cord insertion site and free of maternal decidua, within 15 min of delivery of the placenta. Biopsies were cut into small sections and immediately placed in RNAlater (Thermo Fisher Scientific, Inc., Waltham, MA, USA). Samples were incubated at $4^{\circ} \mathrm{C}$ overnight and stored at $-80^{\circ} \mathrm{C}$ until RNA extraction was performed.

miRNA extraction and quantitative detection. Total RNA was extracted from placental tissue using a MicroRNA Isolation kit (BioTek China, Beijing, China), according to the manufacturer's instructions. Extracted RNA was quantified by measuring absorbance at 260 and $280 \mathrm{~nm}$ using the Nano-200 Micro-Spectrophotometer (Allsheng Instruments, Co., Ltd., Hangzhou, China). Reverse transcription (RT) of miRNA (200 ng) was performed using the ReverTra Ace ${ }^{\circledR}$ qPCR RT kit (Toyobo Co., Ltd., Osaka, Japan) with Bulge-Loop ${ }^{\mathrm{TM}}$ hsa-miR-16-5p (miRQ0000069-1-2), hsa-miR-21-5p (miRQ0000076-1-2), hsa-miR-143-3p (miRQ0000435-1-2) and U6 small nuclear (sn) RNA (MQP-0202) stem-loop RT-primers (Guangzhou RiboBio Co., Ltd., Guangzhou, China), according to the manufacturer's protocol. U6 snRNA was used as an internal control. Reverse transcription-quantitative polymerase chain reaction (RT-qPCR) assay was performed using Thunderbird SYBR qPCR Mix (Toyobo Co., Ltd.) and the CFX96 Touch Real-Time PCR Detection System (Bio-Rad Laboratories, Inc., Hercules, CA, USA), in accordance with the manufacturer's instructions. Cycling conditions were as follows: $95^{\circ} \mathrm{C}$ for $3 \mathrm{~min}$, followed by 30 cycles of $95^{\circ} \mathrm{C}$ for $10 \mathrm{sec}, 60^{\circ} \mathrm{C}$ for $20 \mathrm{sec}$, and $70^{\circ} \mathrm{C}$ for $10 \mathrm{sec}$. To check PCR product homogeneity, the temperature was elevated from 65 to $99^{\circ} \mathrm{C}$ in $0.1^{\circ} \mathrm{C} / \mathrm{sec}$ increments to obtain a melting curve. miRNA expression levels were calculated using the $2^{-\Delta \Delta \mathrm{Cq}}$ method (23).
Bioinformatic prediction of miRNA targets and pathway analysis. miRTarBase (mirtarbase.mbc.nctu.edu.tw, release 4.5) was used to identify target genes (24). DAVID (Database for Annotation, Visualization and Integrated Discovery; david. abcc.ncifcrf.gov) was used to identify pathways involving these target genes (25).

Statistical analysis. Basic characteristics of the macrosomia and control groups were compared using unpaired t-tests for continuous variables and reported as the mean \pm standard deviation. Categorical variables were compared using $\chi^{2}$ tests. The miRNA expression data were not normally distributed, therefore, relative expression was presented as the median (interquartile range) and the Mann-Whitney U test was used to analyze differences in miRNA expression levels between the macrosomia and control groups. miRNA expression levels were divided by quartile, using the lowest quartile as the reference group. Logistic regression models were used to determine the risk factors of giving birth to a newborn with macrosomia. Spearman's correlation coefficients were used to examine the relationship between miR-21 and -143 expression. All statistical analyses were conducted using SPSS software, version 14.0 (SPSS, Inc., Chicago, IL, USA). All P-values reported were two-tailed, and $\mathrm{P}<0.05$ was considered to indicate a statistically significant difference.

\section{Results}

Subject characteristics. Demographic data are presented in Table I. A total of 131 mothers and their neonates were recruited for the current study. The average birth weight of neonates with macrosomia was 4,303.4 $\pm 219.5 \mathrm{~g}$, while the average weight of control neonates was 3,398.0 $\pm 362.2 \mathrm{~g}$. Maternal weight gain during pregnancy was significantly higher in mothers with macrosomic neonates compared with the control group $(\mathrm{P}<0.001)$, and neonates with macrosomia were more likely to be male $(\mathrm{P}=0.004)$. There were no significant differences in gestational age, maternal weight prior to pregnancy, maternal body mass index (BMI) prior to pregnancy, or maternal age between the macrosomia and control groups.

miRNA expression in macrosomic and control placenta. To determine whether miR-16, -21 or -143 were differentially expressed in macrosomic and control placenta, their expression was measured using RT-qPCR. The Mann-Whitney U-test demonstrated that miR-143 was expressed at lower levels in macrosomic placenta (Fig. 1A; P=0.003), whereas miR-21 expression was significantly higher in macrosomic placenta (Fig. 1B; $\mathrm{P}=0.043$ ) compared with the control samples. However, no significant difference in miR-16 expression levels was detected between the two groups (Fig. 1C; $\mathrm{P}=0.955$ ).

Association of miRNAs with macrosomia. The present study examined whether increased miR-21 expression and decreased miR-143 expression were associated with the likelihood of macrosomia using logistic regression models, and adjusted for potential confounders, including maternal age, weight prior to pregnancy, weight gain during pregnancy, gestational age, infant gender and delivery method. miRNA expression levels were divided by quartile (Table II). As presented in Table II, 
Table I. Characteristics of the study sample.

\begin{tabular}{|c|c|c|c|}
\hline Characteristic & Controls $(n=64)$ & Macrosomia cases $(n=67)$ & P-value \\
\hline Birthweight, $g$ & $3,398.0 \pm 362.2$ & $4,303.4 \pm 219.5$ & $<0.001$ \\
\hline Gestational age, weeks & $39.1 \pm 1.0$ & $39.4 \pm 1.0$ & 0.094 \\
\hline Maternal weight prior to pregnancy, $\mathrm{kg}$ & $52.3 \pm 7.0$ & $54.5 \pm 7.2$ & 0.110 \\
\hline Height, $\mathrm{cm}$ & $159.9 \pm 3.6$ & $160.5 \pm 4.5$ & 0.445 \\
\hline Maternal BMI prior to pregnancy, $\mathrm{kg} / \mathrm{m}^{2}$ & $20.5 \pm 2.7$ & $21.2 \pm 2.8$ & 0.195 \\
\hline Maternal weight gain during pregnancy, $\mathrm{kg}$ & $15.4 \pm 5.7$ & $20.1 \pm 5.7$ & $<0.001$ \\
\hline Maternal age, years & $27.8 \pm 4.4$ & $29.0 \pm 3.8$ & 0.097 \\
\hline \multicolumn{4}{|l|}{ Tobacco during pregnancy, n (\%) } \\
\hline No & $64(100)$ & $67(100)$ & \\
\hline Yes & 0 & 0 & \\
\hline Infant gender, n (\%) & & & 0.004 \\
\hline Male & $30(46.9)$ & $48(71.6)$ & \\
\hline Female & $34(53.1)$ & $19(28.4)$ & \\
\hline Delivery method, n (\%) & & & $<0.001$ \\
\hline Vaginal & $55(85.9)$ & $32(47.8)$ & \\
\hline C-section & $9(14.1)$ & $35(52.2)$ & \\
\hline
\end{tabular}

P-values were obtained using unpaired t-tests for continuous variables and $\chi^{2}$ tests for categorical variables. BMI, body mass index.
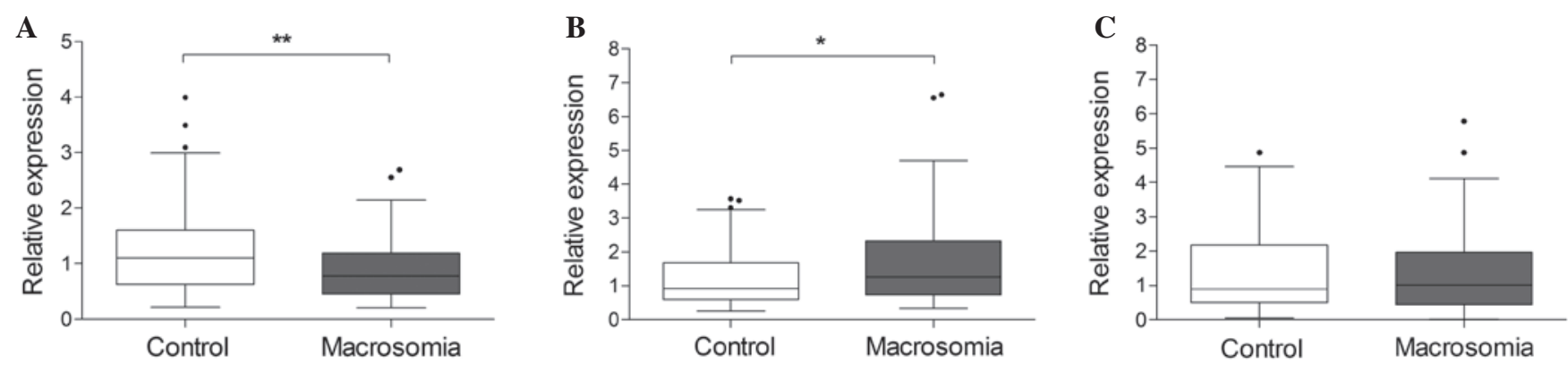

Figure 1. Relative expression of (A) miR-143, (B) miR-21 and (C) miR-16 in placenta. miRNA expression was measured using reverse transcription-quantitative polymerase chain reaction in placenta from macrosomic $(n=67)$ and control $(n=64)$ pregnancies. U6 RNA was used as an internal control. Data are presented as Tukey Box plots. ${ }^{*} \mathrm{P}<0.05$ and ${ }^{* *} \mathrm{P}<0.01$, comparison shown by brackets.

the likelihood of macrosomia increased with miR-21 expression quartile as follows: Q2, OR=6.67 (95\% CI, 1.39-32.05); $\mathrm{Q} 3, \mathrm{OR}=4.10$ (95\% CI, 0.88-19.11); and Q4, OR=16.19 (95\% CI, 2.46-106.68). Conversely, higher miR-143 quartiles were associated with protection against macrosomia as follows: $\mathrm{Q} 2, \mathrm{OR}=0.22$ (95\% CI, 0.049-0.98); Q3, OR=0.11 (95\% CI, 0.024-0.55); and Q4 OR=0.16 (95\% CI, 0.032-0.79). High maternal weight gain during pregnancy and male gender were also demonstrated to be risk factors for macrosomia.

Interaction between miR-21 and -143. Low miR-143 and high miR-21 expression levels were associated with an increased risk of developing macrosomia. Therefore, the current study analyzed the interaction between the expression of the two miRNAs and macrosomia risk (Table III). Logistic regression analysis demonstrated no significant difference in the risk of developing macrosomia among samples with high miR-143 and low miR-21, high miR-143 and high miR-21 or low miR-143 and low miR-21 levels. However, low placental
miR-143 combined with high miR-21 levels were associated with increased likelihood of macrosomia $(\mathrm{OR}=26.47,95 \% \mathrm{CI}$, 2.91-240.79). This suggested an interaction between miR-21 and -143 expression in macrosomia risk.

Correlation between miR-143 and miR-21 expression. As low miR-143 and high miR-21 levels were demonstrated to be associated with macrosomia risk, the current study analyzed whether miR-143 and -21 levels were inversely correlated in macrosomic placenta. However, the microRNAs were positively correlated in macrosomia samples (Spearman $r_{s}=0.43$; $\mathrm{P}<0.001$; Fig. 2A) Levels of miR-143 and miR-21 were not correlated in the control group ( $\mathrm{P}>0.05$; Fig. 2B).

Pathway analysis. To understand the potential mechanisms by which miR-143 and -21 function in shaping macrosomia risk, the present study identified their potential target genes using miRTarBase, a database that provides experimentally validated miRNA-target interactions. The database suggested 
Table II. Results of logistic regression models investigating the association between individual miRNA expression and macrosomia $^{\mathrm{a}}$.

A, $\operatorname{miR}-21$

\begin{tabular}{|c|c|c|c|c|}
\hline Effect & $\mathrm{n}(\%)$ & $\chi^{2}$ & OR $(95 \% \mathrm{CI})$ & P-value \\
\hline miR-21 relative expression quartiles & & & & 0.025 \\
\hline $\mathrm{Q} 1, \leq 0.67$ & $28(25)$ & & 1.00 & \\
\hline Q2, 0.68-1.10 & $27(24)$ & 5.61 & $6.67(1.39-32.05)$ & 0.018 \\
\hline Q3, 1.11-1.95 & $33(30)$ & 3.22 & $4.10(0.88-19.11)$ & 0.073 \\
\hline $\mathrm{Q} 4,>1.95$ & $23(21)$ & 8.38 & $16.19(2.46-106.68)$ & 0.004 \\
\hline Maternal weight gain during pregnancy ${ }^{\mathrm{b}}$ & & & & 0.025 \\
\hline Low & $16(16)$ & & 1.00 & \\
\hline Moderate & $34(34)$ & 5.87 & $3.20(0.481-21.25)$ & 0.229 \\
\hline High & $55(50)$ & 3.48 & $9.78(1.55-61.90)$ & 0.015 \\
\hline Infant gender & & & & 0.002 \\
\hline Female & $46(41)$ & & 1.00 & \\
\hline Male & $65(59)$ & 9.29 & $6.36(1.94-20.90)$ & 0.002 \\
\hline
\end{tabular}

B, miR-143

\begin{tabular}{|c|c|c|c|c|}
\hline Effect & $\mathrm{n}(\%)$ & $\chi^{2}$ & OR $(95 \% \mathrm{CI})$ & $\mathrm{P}$-value \\
\hline miR-143 relative expression quartiles & & & & 0.042 \\
\hline $\mathrm{Q} 1, \leq 0.52$ & $27(24)$ & & 1.00 & \\
\hline Q2, 0.53-0.90 & $29(26)$ & 3.92 & $0.22(0.049-0.98)$ & 0.048 \\
\hline Q3, 0.91-1.35 & $29(26)$ & 7.33 & $0.11(0.024-0.55)$ & 0.007 \\
\hline $\mathrm{Q} 4,>1.35$ & $27(24)$ & 5.08 & $0.16(0.032-0.79)$ & 0.024 \\
\hline Maternal weight gain during pregnancy ${ }^{\mathrm{b}}$ & & & & 0.010 \\
\hline Low & $18(16)$ & & 1.00 & \\
\hline Moderate & $38(34)$ & 6.60 & $3.76(0.488-28.95)$ & 0.204 \\
\hline High & $56(50)$ & 5.07 & $14.43(1.88-110.49)$ & 0.010 \\
\hline Infant gender & & & & 0.015 \\
\hline Female & $46(41)$ & & 1.00 & \\
\hline Male & $66(59)$ & 5.91 & $4.05(1.31-12.52)$ & 0.015 \\
\hline
\end{tabular}

${ }^{a}$ Models adjusted for maternal weight prior to pregnancy, gestational age, delivery method and maternal age. Samples lacking values for one or more covariates were excluded from the model. ${ }^{b}$ Maternal weight gain during pregnancy was divided according to Institute of Medicine recommendations (22). OR, odds ratio; CI, confidence interval.

489 target genes for miR-21 and 20 for miR-143 (Table IV). Potential signaling pathways associated with the target genes, generated by DAVID, are presented in Fig. 3. Identified target genes for miR-21 and -143 included those associated with the mitogen-activated protein kinase (MAPK) signaling pathway, an important pathway in cellular proliferation, growth and apoptosis.

\section{Discussion}

As the mediator between mother and fetus, the placenta secretes various hormones, delivers nutrients to the fetus, facilitates gas exchange and serves as a barrier to protect the fetus from adverse environmental conditions, thus, is crucial for fetal development (26). Previous studies have demonstrated that aberrant miRNA expression in the placenta was associated with preeclampsia (19), intrauterine growth retardation and large birth size (18). The results of the current study indicated that dysregulation of miR-21 and -143 expression was associated with macrosomia, and that there was an association between the two miRNAs with regards to risk of macrosomia. Collectively, the evidence suggested that aberrant placental miRNA expression serves a prominent role in abnormal fetal development.

miR-21 is established as an oncogene that is important during tumor progression (27). In previous studies, the upregulation of miR-21 in esophageal squamous cell carcinoma induced cell proliferation and invasion (28), and anti-miR-21 inhibited cell growth in breast tumor tissue (29). In addition, aberrant expression of miR-21 has been demonstrated 
Table III. Interaction between miR-143 and miR-21 expression and macrosomia ${ }^{\mathrm{a}}$

\begin{tabular}{|c|c|c|c|c|}
\hline Effect & $\mathrm{n}(\%)$ & $\chi^{2}$ & OR $(95 \% \mathrm{CI})$ & P-value \\
\hline miR-143 & & & & 0.005 \\
\hline High & $54(48.6)$ & & 1.00 & \\
\hline Low & $57(51.4)$ & 7.74 & $5.87(1.69-20.44)$ & 0.005 \\
\hline $\operatorname{miR}-21$ & & & & 0.018 \\
\hline Low & $57(51.4)$ & & 1.00 & \\
\hline High & $54(48.6)$ & 5.64 & $4.59(1.31-16.15)$ & 0.018 \\
\hline miR-143 and miR-21 & & & & $0.032^{\mathrm{b}}$ \\
\hline High miR-143, low miR-21 & $17(15.3)$ & & 1.00 & \\
\hline High miR-143, high miR-21 & $37(33.4)$ & 1.92 & $3.57(0.59-21.63)$ & 0.166 \\
\hline Low miR-143, low miR-21 & $40(36.0)$ & 2.65 & $4.53(0.74-27.95)$ & 0.103 \\
\hline Low miR-143, high miR-21 & $17(15.3)$ & 8.46 & $26.47(2.91-240.79)$ & 0.004 \\
\hline
\end{tabular}

${ }^{a}$ Models adjusted for maternal weight prior to pregnancy, maternal weight gain during pregnancy, gestational age, delivery method, infant gender, and maternal age. Samples lacking one or more covariate values were excluded from the model. Expression levels were cut-off by median. ${ }^{\mathrm{b}} \mathrm{P}-\mathrm{value}$ for trend. OR, odds ratio; $\mathrm{CI}$, confidence interval.

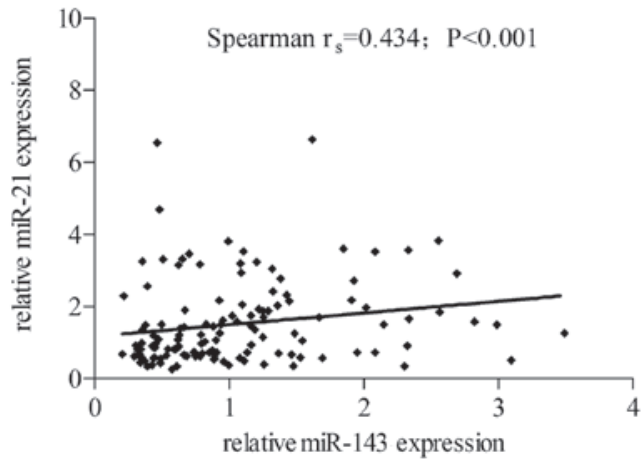

B

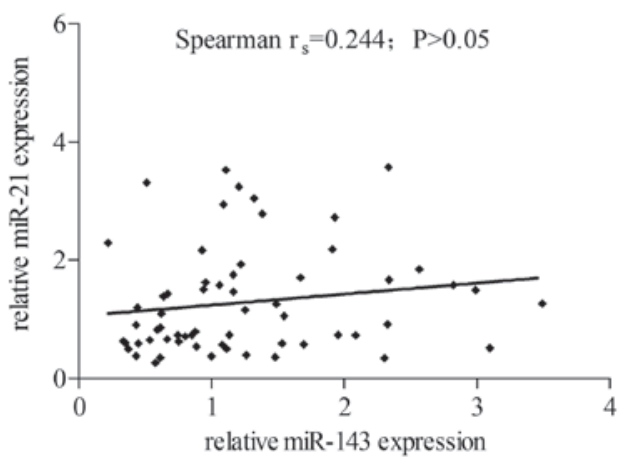

Figure 2. (A) Positive correlation between miR-21 and miR-143 expression in placenta from macrosomic pregnancies (P<0.001). (B) No correlation was observed in the control group $(\mathrm{P}>0.05)$.

A

Glycerophospholipid metabolism(6) Valine leucine and isoleucine biosynthesis(3) TGF-beta signaling pathway $(8)$ Apoptosis (8) Jak-STAT signaling pathway $(9)$ p53 signaling pathway(8) MAPK signaling pathway(21) Pathways in cancer(30)

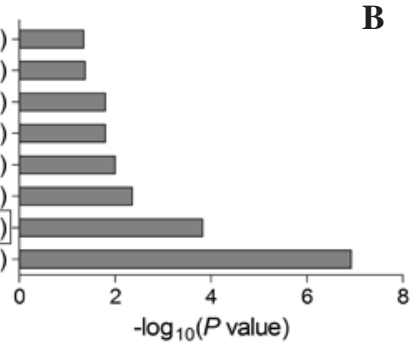

B

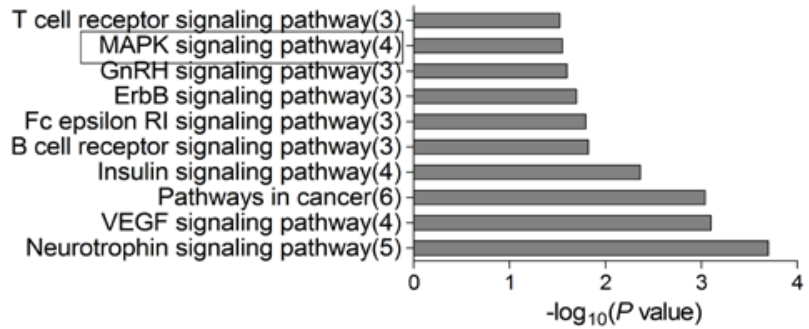

Figure 3. Possible pathways regulated by (A) miR-21 and (B) miR-143. The number of enriched genes for each pathway is indicated in parentheses on the vertical axis. The horizontal axis denotes enrichment score $\log _{10}$ (P-value). For each pathway shown, $\mathrm{P}<0.05$. TGF- $\beta$, transforming growth factor- $\beta$; Jak-STAT, Janus kinase-signal transducer and activator of transcription; MAPK, mitogen-activated protein kinase; GnRH, gonadotropin releasing hormone; VEGF, vascular endothelial growth factor.

to affect apoptosis and metastasis in glioma and colorectal cancer cells $(30,31)$. Placental and cancer cells share numerous similar features, including proliferative, invasive and migratory capacity, and shared epigenetic mechanisms for regulating trophoblast invasion $(32,33)$. Thus, the present study hypothesized that miR-21 may affect placental function by influencing cellular processes such as proliferation, thereby affecting fetal development. The data demonstrated that placental miR-21 expression was upregulated in macrosomia cases, which is consistent with a previous investigation (34). Maccani et al (20) reported that low placental miR-21 expression was a risk factor for small for gestational age (SGA). 
Table IV. Representative target genes of miR-21 and miR-143.

\begin{tabular}{|c|c|c|c|}
\hline \multicolumn{2}{|r|}{ miR-21 target gene } & \multicolumn{2}{|r|}{ miR-143 target gene } \\
\hline Gene ID & Official full name & Gene ID & Official full name \\
\hline PLPP1 & Phospholipid phosphatase 1 & KRAS & Kirsten rat sarcoma viral oncogene homolog \\
\hline PLD2 & Phospholipase D2 & KLF4 & Kruppel-like factor 4 \\
\hline BCAT1 & Branched chain amino-acid transaminase 1 & MYO6 & Myosin VI \\
\hline LARS & Leucyl-tRNA synthetase & DNMT3A & DNA (cytosine-5-)-methyltransferase $3 \alpha$ \\
\hline PDHA2 & Pyruvate dehydrogenase (lipoamide) $\alpha 2$ & FNDC3B & Fibronectin type III domain containing 3B \\
\hline TGFB1 & Transforming growth factor $\beta 1$ & MAPK7 & Mitogen-activated protein kinase 7 \\
\hline TGFBR2 & Transforming growth factor $\beta$ receptor II & $\mathrm{COX} 2$ & Cytochrome c oxidase subunit II \\
\hline SP1 & Sp1 transcription factor & COL1A1 & Collagen, type I, $\alpha 1$ \\
\hline MYC & $\begin{array}{l}v \text {-myc avian myelocytomatosis } \\
\text { viral oncogene homolog }\end{array}$ & HRAS & Harvey rat sarcoma viral oncogene homolog \\
\hline FAS & Fas cell surface death receptor & FSCN1 & Fascin actin-bundling protein 1 \\
\hline IL1B & Interleukin $1 \beta$ & HK2 & Hexokinase 2 \\
\hline BCL2 & B-cell CLL/lymphoma 2 & SERPINE1 & Serpin peptidase inhibitor, clade E, member 1 \\
\hline STAT3 & $\begin{array}{l}\text { Signal transducer and activator } \\
\text { of transcription } 3\end{array}$ & FHIT & Fragile histidine triad \\
\hline PIAS3 & Protein inhibitor of activated STAT3 & MACC1 & Metastasis associated in colon cancer 1 \\
\hline AKT2 & $\begin{array}{l}v \text {-akt murine thymoma viral oncogene } \\
\text { homolog } 2\end{array}$ & PTGS2 & Prostaglandin-endoperoxide synthase 2 \\
\hline PTEN & Phosphatase and tensin homolog & JAG1 & Jagged 1 \\
\hline CDK6 & Cyclin-dependent kinase 6 & AKT1 & $v$-akt murine thymoma viral oncogene homolog 1 \\
\hline MAPK3 & Mitogen-activated protein kinase 3 & MDM2 & MDM2 proto-oncogene E3 ubiquitin protein ligase \\
\hline WNT5A & $\begin{array}{l}\text { Wingless-type MMTV integration site } \\
\text { family member } 5 \mathrm{~A}\end{array}$ & BCL2 & B-cell CLL/lymphoma 2 \\
\hline EGFR & Epidermal growth factor receptor & MMP13 & Matrix metallopeptidase 13 \\
\hline
\end{tabular}

Similarly, a study in mice demonstrated that miR-21 inhibition reduced obesity through the reduction of adipocyte size (35). Other reports have indicated that miR-21 regulated adipogenesis in human primary adipocytes and that its expression was positively correlated with BMI (36). miR-21 was also reported to regulate adipogenic differentiation and adipose proliferation $(37,38)$. Therefore, the present study hypothesized that the upregulation of placental miR-21 leads to macrosomia by promoting cell differentiation and proliferation. However, further experimental evidence is required to evaluate this.

To date, the role of miR-143 in the placenta has remained unknown. To the best of our knowledge, the current study was the first to demonstrate that placental miR-143 was downregulated in macrosomia. Among the miRNAs associated with human obesity, miR-143 was the first reported to regulate adipocyte differentiation (39). Chen et al (21) observed that decreased miR-143 expression promoted adipogenic growth and differentiation of adipose tissue-derived stromal cells by targeting MAPK kinase 5. Compared with control placenta, placenta from macrosomic pregnancies has greater capacity to support growth and differentiation, as it must provide more space and transport more nutrients to a larger fetus (40). Therefore, it can be explained why miR-143 expression was reduced in macrosomic placenta. Other research has reported miR-143 to be a pivotal regulator of cellular activities, targeting multiple mRNAs involved in cell proliferation, survival and apoptosis. For example, overexpression of miR-143 repressed cell proliferation in melanoma and gastric cancer by targeting syndecan-1 (41) and cyclooxygenase-2 (42), which are also expressed in the placenta $(43,44)$. This may partially explain the downregulation of miR-143 in macrosomic placenta demonstrated in the current study. Consistent with the present results, another investigation demonstrated that miR-143 was downregulated in maternal plasma in macrosomic pregnancies (45). However, an association between miR-143 in maternal plasma and placenta remains unclear.

Another notable observation of the current study was the opposing changes to the miR-21 and -143 levels in association with macrosomia. Similarly, Keller et al (36) reported that the expression of miR-21 was positively correlated with BMI. Expression of miR-21 was higher in the adipocyte tissue of adults with BMI>30 than in that of adults with lower BMIs, whereas miR-143 expression was reduced adults with lower BMIs. The same trend was also been demonstrated in colorectal carcinoma and colorectal liver metastasis tissues, which exhibit overexpression of miR-21 and underexpression of miR-143 relative to control tissues (46). These results suggest a functional correlation between miR-21 and -143 expression, as does the relationship identified by the logistic regression analysis in the current study.

According to DAVID analysis (Fig. 3), miR-21 and -143 were associated with MAPK signaling, which is a pivotal pathway in 
cell proliferation and differentiation. miR-143 has been previously reported to target extracellular signal-regulated kinase 5 (ERK5), a member of the MAPK family that promotes cell proliferation and growth. Overexpression of miR-143 reduced ERK5 expression and activation, thus inhibiting cell proliferation and growth in human colon carcinoma (47). By contrast, miR-21 promoted proliferation of Eca109 cells and inhibited apoptosis by activating the ERK1/2/MAPK pathway (48). Together, these results predict an inverse correlation between levels of miR-143 and -21. Unexpectedly, the current study demonstrated a positive correlation between the two miRNAs in macrosomic but not in control placenta, suggesting that a more complex mechanism co-regulates miR-21 and -143. One such plausible mechanism is proposed as follows: A restrictive correlation between miR-21 and -143 in the regulation of fetal weight. Essentially, the two miRNAs independently and inversely regulate growth in fetuses of normal weight, but in macrosomia the two have a mutually restraining relationship, that is, with the risk factor miR-21 increased, the protective factor miR-143 was also increased, to protect the fetus from overgrowth. This may be a homeostatic mechanism to maintain normal growth in the fetus.

Previous studies have demonstrated that miR-16 targets genes in the pathways regulating numerous cellular processes $(49,50)$. Low levels of placental miR-16 expression are associated with SGA (20). However, the current study did not identify significant differences in placental miR-16 expression between macrosomic and control placenta. In addition, the present study demonstrated that male infants were at a greater risk of developing macrosomia than females. This result is consistent with a number previous reports $(11,51)$. One explanation for this result is that male embryos have a higher rate of cell division and metabolism than female embryos (52).

It is noted that this was a hospital-based case-control study. All subjects were recruited from a large, comprehensive hospital that serves all people in the Wenzhou region. Thus, our data are likely to be representative of the population in the Wenzhou region. Regardless, due to the small sample size, the confidence intervals were relatively large.

In summary, the present study demonstrated that low miR-143 expression and high miR-21 expression are risk factors for macrosomia. Furthermore, there is an association between the two miRNAs and macrosomia. These results provide evidence for the effect of aberrant placental miRNA expression in macrosomia and offer valuable insight into the mechanisms underlying macrosomia. Future studies are required to determine the functional mechanism linking placental miRNA expression to macrosomia and may provide novel information on the potential use of miRNAs as a marker of abnormal fetal growth.

\section{Acknowledgements}

The National Natural Science Foundation of China (no. 81072378), and the Natural Science Funds of Zhejiang (no. Y2101185). We gratefully acknowledge the placenta samples provided by the Department of Obstetrics, Yuying Children's Hospital of Wenzhou Medical University. We also thank the residents of the Wenzhou region for their support for our epidemiological study.

\section{References}

1. Boulet SL, Alexander GR, Salihu HM and Pass M: Macrosomic births in the united states: Determinants, outcomes, and proposed grades of risk. Am J Obstet Gynecol 188: 1372-1378, 2003.

2. Henriksen T: The macrosomic fetus: A challenge in current obstetrics. Acta Obstet Gynecol Scand 87: 134-145, 2008.

3. Zhang X, Decker A, Platt RW, Kramer MS: How big is too big? The perinatal consequences of fetal macrosomia. Am J Obstet Gynecol 198: 517 e1-6, 2008.

4. Alsammani MA and Ahmed SR: Fetal and maternal outcomes in pregnancies complicated with fetal macrosomia. N Am J Med Sci 4: 283-286, 2012.

5. Stotland NE, Caughey AB, Breed EM and Escobar GJ: Risk factors and obstetric complications associated with macrosomia. Int J Gynaecol Obstet 87: 220-226, 2004.

6. Ahlgren M, Wohlfahrt J, Olsen LW, Sørensen TI and Melbye M: Birth weight and risk of cancer. Cancer 110: 412-419, 2007.

7. Boney CM, Verma A, Tucker R and Vohr BR: Metabolic syndrome in childhood: Association with birth weight, maternal obesity, and gestational diabetes mellitus. Pediatrics 115: e290-e296, 2005.

8. Harder T, Plagemann A and Harder A: Birth weight and risk of neuroblastoma: A meta-analysis. Int J Epidemiol 39: 746-756, 2010.

9. Ognjanovic S, Carozza SE, Chow EJ, Fox EE, Horel S, McLaughlin CC, Mueller BA, Puumala S, Reynolds P, Von Behren J and Spector L: Birth characteristics and the risk of childhood rhabdomyosarcoma based on histological subtype. Br J Cancer 102: 227-231, 2010.

10. Yu DM, Zhai FY, Zhao LY, Liu AD, Yu WT, Jia FM, Zhang JG and Li J: Incidence of fetal macrosomia and influencing factors in China in 2006. Chin J Child Health Care 16: 11-13, 2008.

11. Li G, Kong L, Li Z, Zhang L, Fan L, Zou L, Chen Y, Ruan Y, Wang $X$ and Zhang W: Prevalence of macrosomia and its risk factors in china: A multicentre survey based on birth data involving 101,723 singleton term infants. Paediatr Perinat Epidemiol 28: 345-350, 2014.

12. Desgagné V, Hivert MF, St-Pierre J, Guay SP, Baillargeon JP, Perron P, Gaudet D, Brisson D and Bouchard L: Epigenetic dysregulation of the IGF system in placenta of newborns exposed to maternal impaired glucose tolerance. Epigenomics 6: 193-207, 2014.

13. Prickett AR and Oakey RJ: A survey of tissue-specific genomic imprinting in mammals. Mol Genet Genomics 287: 621-630, 2012.

14. Xu X, Yang X, Liu Z, Wu K, Liu Z, Lin C, Wang Y and Yan H: Placental leptin gene methylation and macrosomia during normal pregnancy. Mol Med Rep 9: 1013-1018, 2014.

15. Arora S, Rana R, Chhabra A, Jaiswal A and Rani V: miRNA-transcription factor interactions: A combinatorial regulation of gene expression. Mol Genet Genomics 288: 77-87, 2013.

16. Alvarez-Garcia I and Miska EA: MicroRNA functions in animal development and human disease. Development 132: 4653-4662, 2005.

17. Amiel J, de Pontual L and Henrion-Caude A: miRNA, development and disease. Adv Genet 80: 1-36, 2012.

18. Wang D, Na Q, Song WW and Song GY: Altered expression of miR-518b and miR-519a in the placenta is associated with low fetal birth weight. Am J Perinatol 31: 729-734, 2014.

19. Xu P, Zhao Y, Liu M, Wang Y, Wang H, Li YX, Zhu X, Yao Y, Wang H, Qiao J, et al: Variations of microRNAs in human placentas and plasma from preeclamptic pregnancy. Hypertension 63: 1276-1284, 2014

20. Maccani MA, Padbury JF and Marsit CJ: miR-16 and miR-21 expression in the placenta is associated with fetal growth. PLoS One 6: e21210, 2011.

21. Chen L, Hou J, Ye L, Chen Y, Cui J, Tian W, Li C and Liu L: MicroRNA-143 regulates adipogenesis by modulating the MAP2K5-ERK5 signaling. Sci Rep 4: 3819, 2014.

22. Institute of Medicine: Nutrition During Pregnancy. National Academies Press, Washington D.C., 1990.

23. Livak KJ and Schmittgen TD: Analysis of relative gene expression data using real-time quantitative PCR and the 2(-Delta Delta C(T)) Method. Methods 25: 402-408, 2001.

24. Hsu SD, Tseng YT, Shrestha S, Lin YL, Khaleel A, Chou CH, Chu CF, Huang HY, Lin CM, Ho SY, et al: miRTarBase update 2014: An information resource for experimentally validated miRNA-target interactions. Nucleic Acids Res 42: D78-D85, 2014

25. Huang W, Sherman BT and Lempicki RA: Systematic and integrative analysis of large gene lists using DAVID bioinformatics resources. Nat Protoc 4: 44-57, 2009. 
26. Hogg K, Price EM, Hanna CW and Robinson WP: Prenatal and perinatal environmental influences on the human fetal and placental epigenome. Clin Pharmacol Ther 92: 716-726, 2012.

27. Selcuklu SD, Donoghue MT and Spillane C: miR-21 as a key regulator of oncogenic processes. Biochem Soc Trans 37: 918-925, 2009.

28. Mori Y, Ishiguro H, Kuwabara Y, Kimura M, Mitsui A, Ogawa R, Katada T, Harata K, Tanaka T, Shiozaki M and Fujii Y: MicroRNA-21 induces cell proliferation and invasion in esophageal squamous cell carcinoma. Mol Med Rep 2: 235-239, 2009.

29. Si ML, Zhu S, Wu H, Lu Z, Wu F and Mo YY: miR-21-mediated tumor growth. Oncogene 26: 2799-2803, 2007.

30. Quintavalle C, Donnarumma E, Iaboni M, Roscigno G, Garofalo M, Romano G, Fiore D, De Marinis P, Croce CM and Condorelli G: Effect of miR-21 and $\mathrm{miR}-30 \mathrm{~b} / \mathrm{c}$ on TRAIL-induced apoptosis in glioma cells. Oncogene 32: 4001-4008, 2013.

31. Asangani IA, Rasheed SA, Nikolova DA, Leupold JH, Colburn NH, Post S and Allgayer H: MicroRNA-21 (miR-21) post-transcriptionally downregulates tumor suppressor Pdcd 4 and stimulates invasion, intravasation and metastasis in colorectal cancer. Oncogene 27: 2128-2136, 2008.

32. Ferretti C, Bruni L, Dangles-Marie V, Pecking AP and Bellet D Molecular circuits shared by placental and cancer cells, and their implications in the proliferative, invasive and migratory capacities of trophoblasts. Hum Reprod Update 13: 121-141, 2007.

33. Perry JK, Lins RJ, Lobie PE and Mitchell MD: Regulation of invasive growth: Similar epigenetic mechanisms underpin tumour progression and implantation in human pregnancy. Clin Sci (Lond) 118: 451-457, 2010.

34. Jiang H, Wu W, Zhang M, Li J, Peng Y, Miao TT, Zhu H and $\mathrm{Xu}$ G: Aberrant upregulation of miR-21 in placental tissues of macrosomia. J Perinatol 34: 658-663, 2014.

35. Seeger T, Fischer A, Muhly-Reinholz M, Zeiher AM and Dimmeler S: Long-term inhibition of miR-21 leads to reduction of obesity in $\mathrm{db} / \mathrm{db}$ mice. Obesity (Silver Spring) 22: 2352-2360, 2014.

36. Keller P, Gburcik V, Petrovic N, Gallagher IJ, Nedergaard J, Cannon B and Timmons JA: Gene-chip studies of adipogenesis-regulated microRNAs in mouse primary adipocytes and human obesity. BMC Endocr Disord 11: 7, 2011.

37. Kim YJ, Hwang SH, Cho HH, Shin KK, Bae YC and Jung JS: MicroRNA 21 regulates the proliferation of human adipose tissue-derived mesenchymal stem cells and high-fat diet-induced obesity alters microRNA 21 expression in white adipose tissues. J Cell Physiol 227: 183-193, 2012.

38. Kim YJ, Hwang SJ, Bae YC and Jung JS: MiR-21 regulates adipogenic differentiation through the modulation of TGF-beta signaling in mesenchymal stem cells derived from human adipose tissue. Stem Cells 27: 3093-3102, 2009.
39. Esau C, Kang X, Peralta E, Hanson E, Marcusson EG, Ravichandran LV, Sun Y, Koo S, Perera RJ, Jain R, et al: MicroRNA-143 regulates adipocyte differentiation. J Biol Chem 279: 52361-52365, 2004.

40. Larqué E, Ruiz-Palacios M and Koletzko B: Placental regulation of fetal nutrient supply. Curr Opin Clin Nutr Metab Care 16: 292-297, 2013.

41. Li R, Zhang L, Jia L, Duan Y, Li Y, Wang J, Bao L and Sha N: MicroRNA-143 targets Syndecan-1 to repress cell growth in melanoma. PLoS One 9: e94855, 2014.

42. Wu XL, Cheng B, Li PY, Huang HJ, Zhao Q, Dan ZL, Tian DA and Zhang P: MicroRNA-143 suppresses gastric cancer cell growth and induces apoptosis by targeting COX-2. World J Gastroenterol 19: 7758-7765, 2013

43. Hanna N, Bonifacio L, Reddy P, Hanna I, Weinberger B, Murphy S, Laskin D and Sharma D: IFN-gamma-mediated inhibition of COX-2 expression in the placenta from term and preterm labor pregnancies. Am J Reprod Immunol 51: 311-318, 2004

44. Szabo S, Xu Y, Romero R, Fule T, Karaszi K, Bhatti G, Varkonyi T, Varkonyi I, Krenacs T, Dong Z, et al: Changes of placental syndecan-1 expression in preeclampsia and HELLP syndrome. Virchows Archiv 463: 445-458, 2013.

45. Ge Q, Zhu Y, Li H, Tian F, Xie X and Bai Y: Differential expression of circulating miRNAs in maternal plasma in pregnancies with fetal macrosomia. Int J Mol Med 35: 81-91, 2015.

46. Kulda V, Pesta M, Topolcan O, Liska V, Treska V, Sutnar A, Rupert K, Ludvikova M, Babuska V, Holubec L Jr and Cerny R: Relevance of miR-21 and miR-143 expression in tissue samples of colorectal carcinoma and its liver metastases. Cancer Genet Cytogenet 200: 154-160, 2010.

47. Borralho PM , Simões AE, Gomes SE, Lima RT, Carvalho T, Ferreira DM, Vasconcelos MH, Castro RE and Rodrigues CM: miR-143 overexpression impairs growth of human colon carcinoma xenografts in mice with induction of apoptosis and inhibition of proliferation. PLoS One 6: e23787, 2011.

48. Liu F, Zheng S, Liu T, Liu Q, Liang M, Li X, Sheyhidin I, Lu X and Liu W: MicroRNA-21 promotes the proliferation and inhibits apoptosis in Eca109 via activating ERK1/2/MAPK pathway. Mol Cell Biochem 381: 115-125, 2013.

49. Wang Y, Fan H, Zhao G, Liu D, Du L, Wang Z, Hu Y and Hou Y: miR-16 inhibits the proliferation and angiogenesis-regulating potential of mesenchymal stem cells in severe pre-eclampsia. FEBS J 279: 4510-4524, 2012.

50. Zuo W, Wang ZZ and Xue J: Artesunate induces apoptosis of bladder cancer cells by miR-16 regulation of COX-2 expression. Int J Mol Sci 15: 14298-14312, 2014.

51. Koyanagi A, Zhang J, Dagvadorj A, Hirayama F, Shibuya K, Souza JP and Gülmezoglu AM: Macrosomia in 23 developing countries: An analysis of a multicountry, facility-based, cross-sectional survey. Lancet 381: 476-483, 2013.

52. Mittwoch U: Blastocysts prepare for the race to be male. Human Reprod 8: 1550-1555, 1993. 